Document downloaded from:

http://hdl.handle.net/10251/90962

This paper must be cited as:

Redondo Foj, MB.; Carsí Rosique, M.; Ortiz Serna, MP.; Sanchis Sánchez, MJ.; García, FC.; García. José Miguel (2013). Relaxational study of poly(vinylpyrrolidone-co-butyl acrylate) membrane by dielectric and dynamic mechanical spectroscopy. JOURNAL OF PHYSICS D-APPLIED PHYSICS. 46(29):295304-1-295304-12. doi:doi:10.1088/0022$3727 / 46 / 29 / 295304$

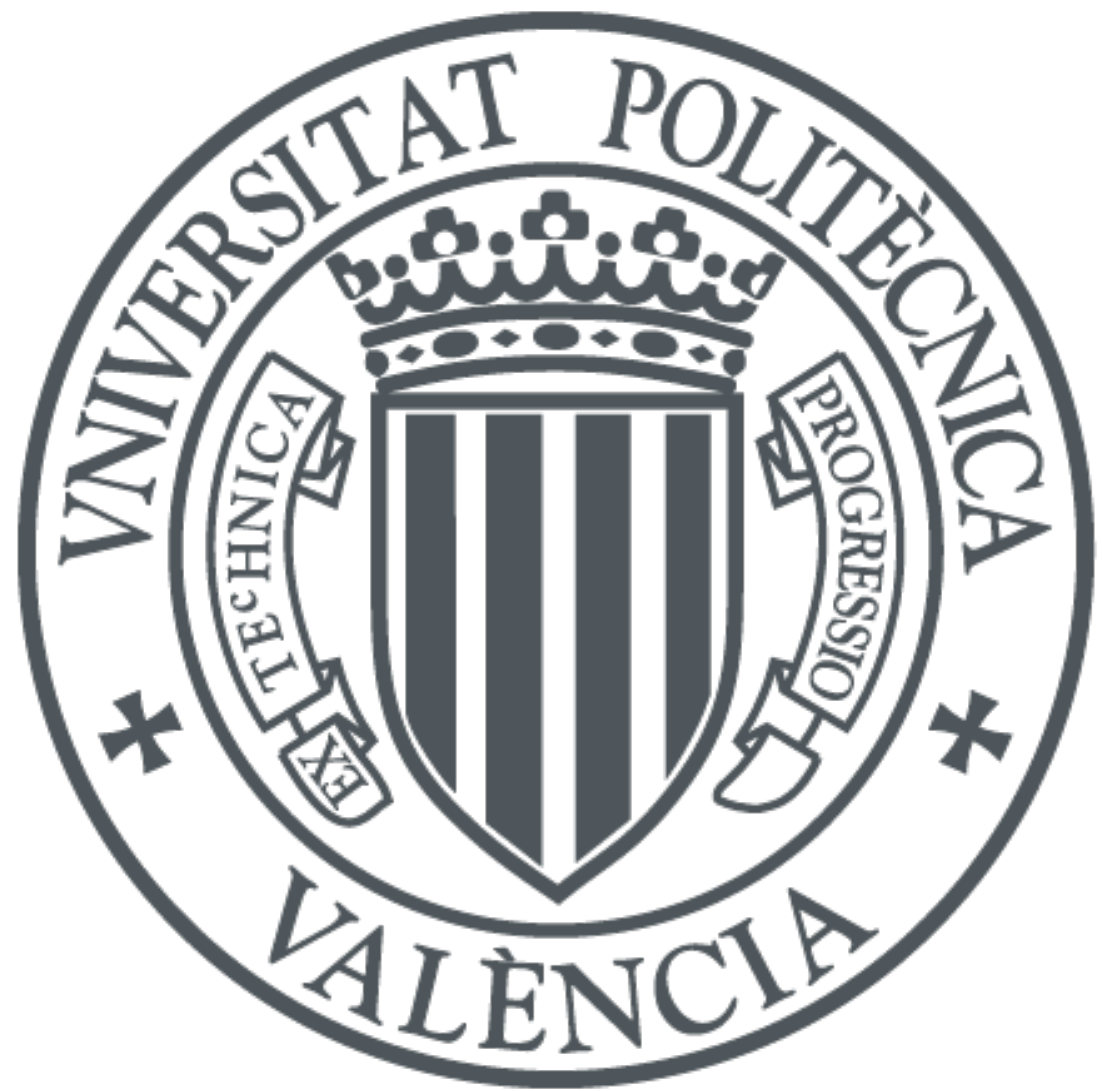

The final publication is available at

http://doi.org/ 10.1088/0022-3727/46/29/295304

Copyright IOP Pub. Co.

Additional Information 


\title{
Relaxational Study of poly(vinylpyrrolidone-co-butyl acrylate) membrane by Dielectric and Dynamic Mechanical Spectroscopy
}

\author{
B Redondo-Foj ${ }^{1}$, M Carsí ${ }^{1}$, P Ortiz-Serna ${ }^{1}$, M J Sanchis ${ }^{*}$, F García ${ }^{2}$ and J M García ${ }^{2}$ \\ ${ }^{1}$ Instituto Tecnológico de la Energía, Departamento de Termodinámica Aplicada, Universitat \\ Politècnica de València, Camí de Vera s/n, 46022, Valencia, Spain. \\ ${ }^{2}$ Universidad de Burgos, Plaza Misael Bañuelos s/n, 09001 Burgos, Spain. \\ *Corresponding author: M.J. Sanchis; Tel.: 0034963879327; email: jsanchis@ter.upv.es
}

\begin{abstract}
A poly(vinylpyrrolidone-co-butyl acrylate) (60VP-40BA) membrane has been synthesized as a tractable and hydrophilic material, obtaining a water swelling percentage around $60 \%$. An investigation of molecular mobility by means of Differential Scanning Calorimetry (DSC), Dynamic Mechanical Analysis (DMA) and Broadband Dielectric Relaxation Spectroscopy (DRS) has been fulfilled in the dry membrane. Dielectric and viscoelastic relaxation measurements have been carried out on the 60VP-40BA sample at several frequencies between $-150^{\circ} \mathrm{C}$ to $150^{\circ} \mathrm{C}$.The dielectric spectrum shows several relaxation processes labelled as $\gamma, \beta$ and $\alpha$ in increasing order of temperature, whereas in the mechanical spectrum only the $\beta$ and $\alpha$ relaxation processes are completely defined. In the dielectric measurements, conductive contributions overlap the $\alpha$-relaxation. The apparent activation energies have similar values for the $\beta$-relaxation in both, the mechanical and the dielectric measurements. The $\beta$ process is related to the local motions of the pyrrolidone group and the $\gamma$ process is connected with the butyl units motions, both located in the side chains of the polymer.
\end{abstract}

PACS: 77.84.Jd, 72.80.Le, 64.70.pj, 77.22.Gm, 62.20.-x, 81.70.Pg

Keywords: Hydrogel, dielectric and mechanical spectroscopy, thermal analysis 


\section{Introduction}

The versatility of gel polymers is well documented in the literature, and has been the subject of a recent review [1-2]. They are versatile materials that can develop very attractive physical and chemical properties. In other words, they form a new class of solids showing sophisticated potentialities for a range of applications [3-6].

A gel is defined as a crosslinked polymeric or copolymeric network, which is characterized by a remarkable ability to absorb a considerable quantity of liquid up to swelling equilibrium, without being dissolved. A polymer is only suitable as a gel network if it has affinity for a solvent. When the swollen liquid is water, the gel polymer is called hydrogel [7]. On the other hand, when a hydrogel is dried, it is called xerogel, or simply a dried hydrogel. The properties of a gel polymer depend largely on the structure of the polymer network. Moreover, the polymer network's mobility depends on its cross-link structure [8]. Thus, the gel polymer can be insoluble due to the presence of chemical or physical crosslinks. The water swollen depends on the chemical composition and also on the crosslinking density. The higher the number of the hydrophilic groups, the higher the water holding capacity is. However, an increase in the crosslinking density produces a decrease in the swelling equilibrium. Some type of hydrogels can be prepared by photopolymerization of the monomer or comonomers in the presence of photoinitiators using visible or ultraviolet (UV) light. The photopolymerization is used in biomedical applications due to its ability to convert a liquid monomer or macromer into a crosslinked network. Another advantage of this procedure is associated with the reduction of possible residual organic solvents involved during the polymerization process [9-10]. In order to obtain the crosslinked network, chemical crosslinking is presented as a highly useful method for creating hydrogels with good mechanical stability [11].

The Polyvinylpyrrolidone (PVP), due to its inherent characteristics, represents a material with a combination of chemical and physical properties which makes it useful in a broad range of technological and biomedical applications. [12-21]. PVP has high chemical stability, good film forming properties and adherence to different substrates and, at the same time, low toxicity and complexing ability. Moreover, it is soluble in water as well as in a number of organic solvents. However, it has limited applicability due to its inherent mechanical properties. For this reason, in order to obtain a membrane with appropriate properties for a specific application and adequate mechanical stability, it is pertinent the preparation of PVP membranes by copolymerization with other materials. In this context, butyl acrylate (BA) is a hydrophobic monomer showing good compatibility with VP, which permits the control of the membrane water swelling and give rise to tractable materials. As a consequence, the vinyl-pyrrolidone/butyl acrylate copolymers have important applications in the photography, lithography, adhesive and pharmaceutical industries [22]. Moreover, copolymerization 
reactions provide an excellent way for the preparation of macromolecules with specific chemical structures and for the control of properties such as hydrophilic/hydrophobic balances, solubility, polarity, etc. [23]. Thus, the investigation of the physical properties of this copolymer is very effective in establishing the structure-properties relationships.

In this sense, the aim of the present work is to analyse the thermal, mechanical and dielectric properties of poly(vinylpyrrolidone-co-butyl acrylate) (60VP-40BA). This study focuses mainly on the analysis and comparison of the 60VP-40BA response to dynamic electric and mechanical fields, both in the glassy state and in the glass-rubber transition zone.

The membrane was prepared by radical polymerization of an appropriate VP-BA molar ratio (60-40) chosen in order to obtain good mechanical and thermal properties. We carried out the dielectric and mechanical analysis by means of Broadband Dielectric Spectroscopy and Dynamic Mechanical Analysis respectively, in a wide range of temperatures and frequencies [24-27]. These techniques yields a wealth of information about of the molecular mobility and this type of information is very useful in order to understand the behaviour of these materials when they are used in their final applications [28]. The intensity of interactions between atoms, ions, or molecules determines the physical structure of the condensed matter. The glass transition is a major phenomenon in condensed matter physics, the precursor of which is the so-called $\alpha$ relaxation. A general feature of polymer chains is the role played by intramolecular interactions in the development of the glass transition. Moreover, secondary relaxations are observed in the response of supercooled liquids to perturbation fields at high frequencies. However, whereas the $\alpha$ relaxation freezes-in at glass transition temperature $\left(T_{g}\right)$, secondary relaxations remain operative in the glassy state. Secondary processes exhibit Arrhenius behaviour with activation energies of the same order as the barrier energy associated with local molecular motions.

It is well known that water has a plasticizing effect on the polymers, reducing the $T_{g}[24,28$ 31]. Moreover, the characterization of the $\alpha$ relaxation, directly related to the glass transition, is sometimes difficult to carry out for wet membranes. This is related to the high intensity of the water conductive effects, which masks or does not allow a clear definition of the $\alpha$ relaxation [25,32-33]. For this reason, in order to analyse the behaviour of the membrane without external agents, the study was carried out in the xerogel and not in the hydrated membrane.

\section{Experimental Section}

\subsection{Membrane preparation and Membrane hydrophilicity characterization}


All chemicals were obtained commercially and used as received: 1-Vinyl-2-pyrrolidone (Aldrich, 99\%), butyl acrylate (Fluka, 99.5\%), ethylene glycol dimethacrylate (Aldrich, 98\%), and 2,2dimethoxy-2-phenylacetophenone (Aldrich, 99\%). Membrane of poly(vinylpyrrolidone-co-butyl acrylate) (60VP-40BA) was prepared by radical polymerization of 1-vinyl-2-pyrrolidone (1) and butyl acrylate (2) mixture with a molar ratio of 60:40. Ethylene glycol dimethacrylate (3) was used as the cross-linking agent (1\% mol percentage regarding the overall comonomer molar content), and 2,2dimethoxy-2-phenylacetophenone (1.56 wt.\%) was used as a radical photoinitiator. The homogenous solution comprised of 1, 2 and 3, and the photoinitiator were transferred to an ampoule, degassed by nitrogen bubbling for $15 \mathrm{~min}$ and injected into an oxygen-free atmosphere $100 \mu \mathrm{m}$ thick silanised glass hermetic mould. In this mould, the photoinitiated bulk polymerization was performed, at $20^{\circ} \mathrm{C}$, for $1 \mathrm{~h}$, upon irradiation with a UV mercury lamp (250W, Philips HPL-N, emission band in the UV region at 304, 314, 335 and $366 \mathrm{~nm}$, with maximum emission at $366 \mathrm{~nm}$ ). Then, the membrane was conditioned by means of a thoroughly washed with acetone (two washing cycles each of $3 \mathrm{~h}$ ) followed by a dried at room temperature and its dip in pure water overnight. Finally, it was dried in a vacuum oven at $20^{\circ} \mathrm{C}$. The final thickness of the membrane was $110 \mu \mathrm{m}$. The chemical structure is depicted in figure 1.
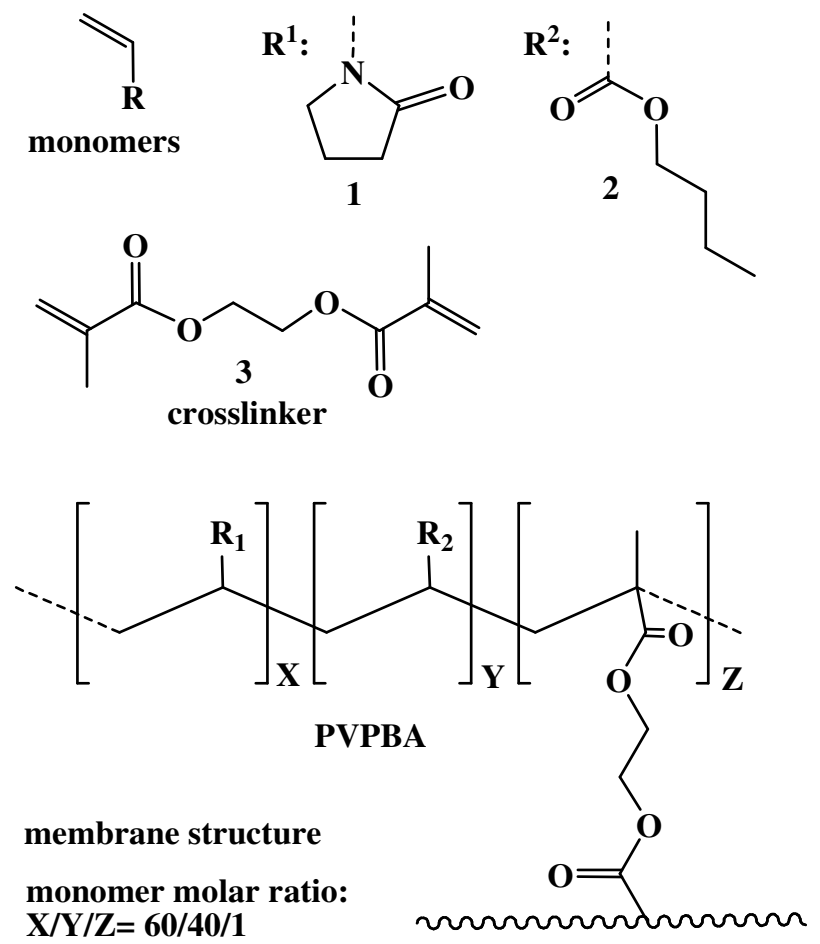

Figure 1. Chemical structures of the comonomers and the dense copolymer membrane.

The membrane was immersed in pure water at $20^{\circ} \mathrm{C}$. The swollen gel was periodically removed from the water bath and was blotted free of surface water with filter paper. Then, the wet gel 
sample was weighted at room temperature and placed in the same bath. The measurements were carried out until reach the swollen equilibrium, i.e. until constant weight. The swollen membrane weight was defined as $w_{s}$. Next, the sample was dried in an air circulating oven at $60^{\circ} \mathrm{C}$ for $2 \mathrm{~h}$ and weighted again $\left(w_{d}\right)$. Finally, the water-swelling percentage (WSP), defined as the weight percentage of water uptake by the film upon soaking until equilibrium, was obtained as follows: $100 \times\left[\left(w_{s}-\right.\right.$ $\left.\left.w_{d}\right) / w_{d}\right]$.

\subsection{Infrared measurements (FT-IR)}

Infrared spectrum (FT-IR) of dried 60VP-40BA membrane was recorded with a JASCO FT/IT-4100 fitted with a PIKE TECH "Miracle" ATR accessory.

\subsection{Thermogravimetric analysis (TGA)}

Thermogravimetric analysis (TGA) data of 60VP-40BA membrane was obtained from $5 \mathrm{mg}$ of previously dried sample under a flow of both, nitrogen and synthetic air, using a TA Instruments Q50 TGA analyser at a scan rate of $10^{\circ} \mathrm{C} / \mathrm{min}$.

\subsection{Differential Scanning Calorimetry measuremets}

Differential scanning calorimetry (DSC) of 60VP-40BA membrane was carried out using a TA Instruments DSC Q-20 differential scanning calorimeter with a refrigerated cooling system. The thin films were repeatedly stacked into a pan, with a weight of $7.9 \mathrm{mg}$. The measurement was conducted in crimpled non-hermetic aluminium pans, using an empty crimpled aluminium pan as the reference cell. The sample was heated from $-80^{\circ} \mathrm{C}$ to $150^{\circ} \mathrm{C}$ at $10^{\circ} \mathrm{C} \cdot \mathrm{min}^{-1}$, cooled to $-80^{\circ} \mathrm{C}$ and reheated at $10^{\circ} \mathrm{C} \cdot \mathrm{min}^{-1}$ to $200^{\circ} \mathrm{C}$. The first run was carried out to remove all the residual moisture and to erase the effect of previous thermal history. The DSC test was performed under a $50 \mathrm{ml} \cdot \mathrm{min}^{-1}$ flow of nitrogen to prevent oxidation. High-purity indium was used to calibrate the DSC cell. The glass transition temperature was evaluated as the intersection of the base line of the glassy region with the tangent to the endotherm in the middle points.

\subsection{Dynamic mechanical measurements}


In order to determine the tensile properties of the membrane, strips ( $5 \mathrm{~mm}$ in width, $30 \mathrm{~mm}$ in length, and 100-120 $\mu \mathrm{m}$ thick) were cut from the polymer film and measured using a Hounsfield H10KM Universal Testing Dynamometer at $20^{\circ} \mathrm{C}$. Mechanical clamps held the sample and an extension rate of $5 \mathrm{~mm} \cdot \mathrm{min}^{-1}$ was applied using a gauge length of $10 \mathrm{~mm}$. Six membranes were tested and the data were averaged. The estimated water content of the membranes, due to the ambient humidity, was $2 \%$. This water percentage was calculated as the difference between the weights of the wet and the oven dry samples. The sample was dried at $100^{\circ} \mathrm{C}$ until constant weight.

Dynamic mechanical measurements of 60VP-40BA membrane was performed in a Dynamic Mechanical Analyser (TA Instruments DMA Q800) in the tension mode on moulded probes of $6.5 \times 8 \times 0.09 \mathrm{~mm}$, over the temperature range from $-150^{\circ} \mathrm{C}$ to $140^{\circ} \mathrm{C}$. Sample was dried in an aircirculating oven at $45^{\circ} \mathrm{C}$ for fifteen days in order to remove moisture or low molecular weight compounds and also was heated in the DMA oven, at $120^{\circ} \mathrm{C}$ for 10 minutes before the measurements. Measurements were carried out at $1^{\circ} \mathrm{C} \cdot \mathrm{min}^{-1}$ heating rate, at frequencies of $0.3,1,3,10$ and $30 \mathrm{~Hz}$.

\subsection{Dielectric measurements}

The experimental dielectric behaviour of 60VP-40BA membrane was studied with a Novocontrol Broadband Dielectric Spectrometer (Hundsagen, Germany) consisting of an Alpha analyser, to carry out measurements from $5 \cdot 10^{-2}$ to $3 \cdot 10^{6} \mathrm{~Hz}$. The measurements were carried out in inert $\mathrm{N}_{2}$ atmosphere between $-150^{\circ} \mathrm{C}$ to $150^{\circ} \mathrm{C}$. The temperature was controlled by a nitrogen jet (QUATRO from Novocontrol) with a temperature error of $0.1^{\circ} \mathrm{C}$ during every single sweep of frequency. Moulded disc shaped samples of about $0.1 \mu \mathrm{m}$ thickness and $20 \mathrm{~mm}$ diameter was used. The experimental uncertainty was better than $5 \%$ in all cases.

\section{Results and discussion}

\subsection{Membrane hydrophilicity}

The WSP of 60VP-40BA membrane was $60 \%$, pointing out a gel behaviour of the sample. The hydrophilic character of a membrane may be tuned by means of two non-exclusive ways: the balance of hydrophilic to hydrophobic comonomer ratio and the cross-linking percentage [34]. As mentioned before, the chemical composition of $60 \mathrm{VP}-40 \mathrm{BA}$ membrane was chosen to obtain an optically transparent and tractable material, both in the dry and in the water-swelled state, with good mechanical and thermal properties. 
The WSP is a key parameter in biological applications of polymers. The higher is the WSP, the better is the biocompatibility. However, the water uptake in aqueous media impairs the mechanical performance of the materials. Thus, it is important to find equilibrium between the WSP and the mechanical performance, especially in the VP case, a highly hydrophilic monomer. Therefore, we have controlled both parameters by means of: a) the use of a hydrophobic comonomer, butyl acrylate; and b) the preparation of a network employing a cross-linker, 2,2-dimethoxy-2-phenylacetophenone. The chemical structure of the membrane was designed to render a WSP between 50-70\%, water uptake needed for some specific applications, e.g. soft lenses usually contain between $50 \%$ and $60 \%$ water content and some contain over 70\% [35]. Moreover, the water swollen membrane was a highly tractable material with fairly the same mechanical properties that the dried membranes. Furthermore, due to the cross-linking, it was observed that the swollen membrane retained its shape and was water insoluble.

\subsection{Infrared measurements (FT-IR)}

The FTIR spectra of the membrane showed the characteristic absorption bands corresponding to the functional groups present in the chemical structure of the material. The assignment of these bands is depicted in figure 2 . The two $v_{\mathrm{C}=\mathrm{O}}$ bands are ascribed to the majority pendant lactam structure (lower energy band, amide I), and to the pendant butyl ester structure and to the cross-linker agent (higher energy band).

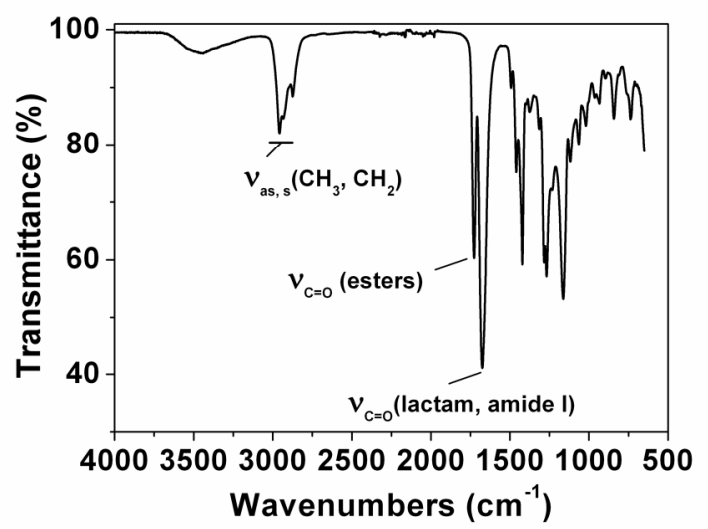

Figure 2. FTIR spectra of the dried membrane.

\subsection{Thermogravimetric analysis (TGA)}

The thermal stability of the membrane was evaluated using TGA. Figure 3 shows the curves of the weight loss as a function of the temperature under two different atmospheres. These curves exhibit a first weight loss at $200^{\circ} \mathrm{C}$, about $2 \%$, which was attributed to the non-reticulated chain ends [36]. 
Increasing the temperature, both curves show a weight loss of $5 \%$ and $10 \%$, at $349^{\circ} \mathrm{C}$ and $370^{\circ} \mathrm{C}$ in inert atmosphere and $291^{\circ} \mathrm{C}$ and $333^{\circ} \mathrm{C}$ in oxidizing atmosphere, respectively. The difference between oxidizing and inert atmosphere at temperatures lower than $400^{\circ} \mathrm{C}$, could be attributed to the weight loss caused by the oxidative breakage of the pendant linear aliphatic chains, corresponding to the butyl ester structure. According to our results the membrane had reasonably good thermal stability.

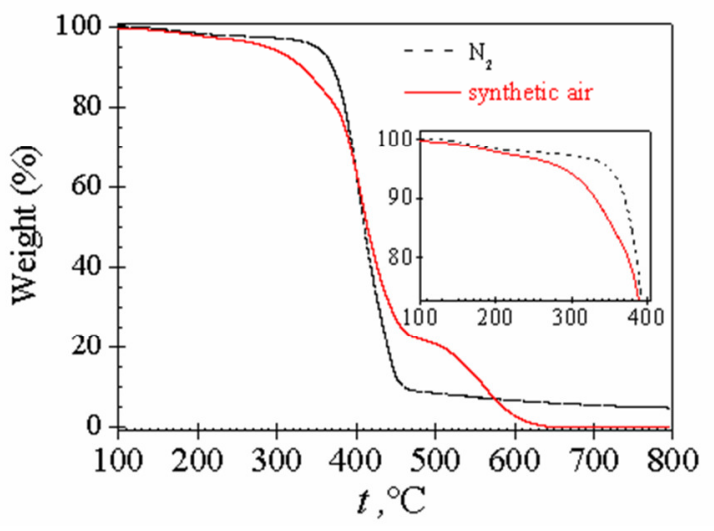

Figure 3. TGA curves of the membranes in inert (nitrogen) and oxidizing (synthetic air) atmosphere.

\subsection{Differential Scanning Calorimetry measurements}

The DSC thermograms are plotted in figure 4 . The first heating ramp exhibits a step at $24.4^{\circ} \mathrm{C}$, signifying the rubber glass temperature $\left(T_{g}\right)$ and an endothermic peak at about $100^{\circ} \mathrm{C}$ associated with the presence of humidity. This peak is quite broad because water evaporation takes place over a wide range of temperatures. From the heat of evaporation of bulk water $\left(2400 \mathrm{~J} / \mathrm{g}\right.$ at $\left.100^{\circ} \mathrm{C}\right)$, we estimated the amount of moisture present in the sample at $2 \%$. On the other hand, in the thermogram corresponding to the second heating ramp only the 60VP-40BA membrane glass temperature is evident (at $36.1^{\circ} \mathrm{C}$ ). Clearly this value is higher than the glass temperature measured on the first heating ramp, due to the plasticizing effect of water. 


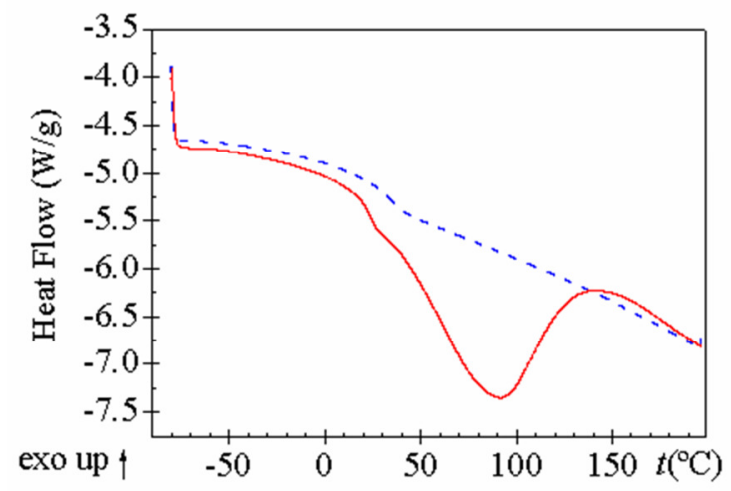

Figure 4. DSC curves taken at $10^{\circ} \mathrm{C} \cdot \mathrm{min}^{-1}$ of $60 \mathrm{VP}-40 \mathrm{BA}$ membrane. (Continuous curve: first heating ramp and dashed curve: second heating ramp)

\subsection{Dynamic mechanical measurements}

Mechanical and thermal resistances are key parameters to determine the suitability of an organic material for technological applications. From a mechanical point of view, the 60VP-40BA dense membrane showed a good performance. The Young's modulus was $200 \mathrm{MPa}$, the tensile strength was $15 \mathrm{MPa}$ and the elongation at break was $540 \%$ at room temperature with a water content of $2 \%$ due to the ambient humidity. The drying of the hydrophilic membrane, at $90^{\circ} \mathrm{C}$ for $1 \mathrm{~h}$, did not significantly change the above mentioned parameters.

In order to evaluate the dependence of the mechanical properties with the time and the temperature, dynamic measurement was carried out by DMA. Figure 5 shows the storage and loss modulus isochrones for $60 \mathrm{VP}-40 \mathrm{BA}$ membrane, over the temperature window $-150^{\circ} \mathrm{C}-150^{\circ} \mathrm{C}$ at $0.3,1$, 3,10 and $30 \mathrm{~Hz}$. The loss isochrones show three distinct relaxation peaks $(\alpha, \beta$ and $\gamma)$ in a decreasing temperature order. Around $37^{\circ} \mathrm{C}(1 \mathrm{~Hz})$, the dynamic mechanical response is dominated by the $\alpha$ peak related to the glass-rubber relaxation, and at lower temperatures, in the glassy state, a broad absorption centred around $-97^{\circ} \mathrm{C}$ appears. This absorption is labelled $\beta$ relaxation. Finally, the loss isochrones show the presence of a $\gamma$ relaxation process below $-140^{\circ} \mathrm{C}$, but unfortunately this process is not fully defined in the experimental range of temperature. As would be expected, the location of both, $\alpha$ and $\beta$ peaks, is shifted to higher temperatures as frequency increases, and the intensity of the peaks remains nearly constant as the frequency of the isochrones increases. 


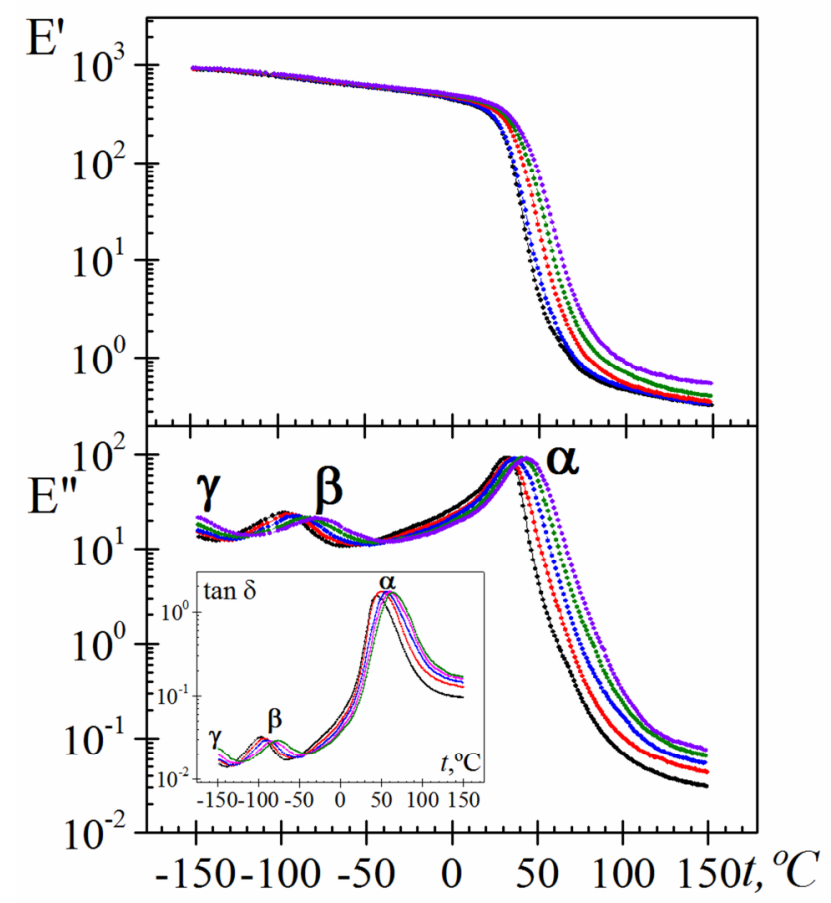

Figure 5. Temperature dependence of storage and loss modulus for 60VP-40BA membrane at $0.3,1$, 3,10 and $30 \mathrm{~Hz}$.

In order to characterize and analyse the observed relaxations in the mechanical spectrum, it is convenient to choose a model which appropriately reproduces the experimental data. A reliable model to represent the secondary relaxations in polymers is the Fuoss and Kirkwood equation [37]. This semi-empirical model has extensively been used in the representation of the mechanical relaxations and can be written in the temperature dependence as

$$
E^{\prime \prime}=E_{\text {max }}^{\prime \prime} \cdot \operatorname{sech}\left[\frac{m \cdot E_{a}}{R}\left(\frac{1}{T}-\frac{1}{T_{\max }}\right)\right]
$$

where $E^{\prime \prime}$ represents the mechanical loss, $E^{\prime \prime}{ }_{\max }$ is the value of this quantity at the peak maximum, $T_{\max }$ is the temperature of the peak maximum, $E_{a}$ is the apparent activation energy, $R$ is the gas constant, and $m$ is a parameter $(0<m<1)$ related to the broadness of the relaxation in the sense that the lower $m$, the wider the distribution is. The value of $m=1$ corresponds to a single relaxation time (Debye peak). The strength of the mechanical relaxation peak can be calculated from the relationship [38], $E_{\max }^{\prime \prime}$ $=m \cdot \Delta E / 2$, where $\Delta E$ represents $\left(E_{0}-E_{\infty}\right)$.

The function was determined from a multiple nonlinear regression analysis of the experimental data, allowing the three characterizing peak parameters $\left(i . e . E_{\max }^{\prime \prime},\left(m \cdot E_{d} / R\right), T_{\max }\right)$ to 
vary. Table 1 compiles the fit parameters corresponding at all the experimental frequencies studied and the corresponding values of $m$. The variation of the relaxation times with temperature for the $\beta$ process is shown in figure 6. It can be seen that the relaxation times follows an Arrhenius behaviour with activation energy of $59.8 \pm 0.1 \mathrm{~kJ} \cdot \mathrm{mol}^{-1}$.

Table 1. Fuoss and Kirkwood fit parameters of $\beta$ relaxation for 60VP-40BA membrane.

\begin{tabular}{llllll}
\hline $\boldsymbol{f , H z}$ & $\boldsymbol{E}_{\max }^{\prime \prime}, \boldsymbol{M P a}$ & $\boldsymbol{m}_{\boldsymbol{\beta}} \boldsymbol{E}_{\boldsymbol{a}} / \boldsymbol{R}, \boldsymbol{K}$ & $\mathbf{T}_{\max , \boldsymbol{\beta}} \boldsymbol{K}$ & $\boldsymbol{m}_{\boldsymbol{\beta}}$ & $\boldsymbol{\Delta E}, \boldsymbol{M P a}$ \\
\hline 0.3 & $24.2 \pm 0.2$ & $1804.9 \pm 44.0$ & $171.8 \pm 0.2$ & $0.25 \pm 0.01$ & $193.0 \pm 3.4$ \\
1 & $23.4 \pm 0.1$ & $1954.6 \pm 60.1$ & $176.8 \pm 0.2$ & $0.27 \pm 0.01$ & $172.2 \pm 4.5$ \\
3 & $22.1 \pm 0.1$ & $1705.0 \pm 21.7$ & $181.2 \pm 0.1$ & $0.24 \pm 0.01$ & $187.0 \pm 2.0$ \\
10 & $21.1 \pm 0.1$ & $1618.1 \pm 25.9$ & $186.9 \pm 0.1$ & $0.22 \pm 0.01$ & $187.9 \pm 2.3$ \\
30 & $21.0 \pm 0.1$ & $1646.2 \pm 42.2$ & $193.2 \pm 0.2$ & $0.23 \pm 0.01$ & $183.3 \pm 3.9$ \\
\hline
\end{tabular}

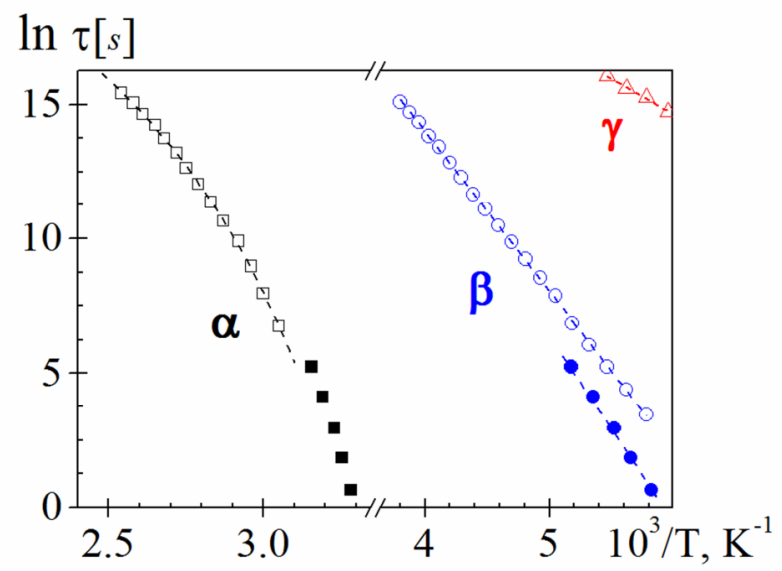

Figure 6. Arrhenius plot for the $\alpha$ (squares), $\beta$ (circles) and $\gamma$ (triangles) relaxations for 60VP-40BA membrane. Open symbols for dielectric results and full symbols for mechanical results.

As we can observe in table 1 , the values of $m_{\beta}$ parameter do not show a noticeable dependence on the frequency of the isochrones. The low values obtained for this parameter seem to be an indication of the distributed character of the process. According to our results, the $\Delta E_{\beta}$ value remains nearly constant with the increasing frequency.

It is well known that the relaxations associated with the glass transition follow a behaviour defined by the Vogel-Fulcher-Tammann-Hesse (VFTH) equation [24-26,39-43]: 


$$
\ln f=A-\left[\frac{M}{T_{\max }-T_{v}}\right]
$$

where $A$ and $M$ are constants, $T_{\max }$ is the temperature of the $E^{\prime \prime}$ maximum peak and $T_{v}$ is the Vogel Temperature. $T_{v}$ is currently associated with the temperature at which the entropies of the glassy system and the crystal are similar, i.e. when the configurational entropy of the glassy system is zero. The parameters of eq. (2) that fit the Arrhenius plots (see figure 6) are $A=(25.1 \pm 0.6), M=$ $(1510.9 \pm 35.9) \mathrm{K}$ and $T_{v}=(247.0 \pm 0.1) \mathrm{K}$. As usual, the results for $T_{v}$ are nearly $50 \mathrm{~K}$ below those of $T_{g}$.

By comparing eq (2) with the Doolittle expression [44-45], the fraction of free volume at the glass transition temperature, $\phi_{g} / B$, and the free volume expansion coefficient $\alpha_{f}=(1 / V)(\partial V / \partial T)_{p}$ are estimated from the following expressions

$$
\begin{aligned}
& \frac{\phi_{g}}{B}=\frac{T_{g}-T_{v}}{M} \\
& \frac{\alpha_{f}}{B}=\frac{1}{M}
\end{aligned}
$$

According to the Cohen-Turbull theory, $B$ is a parameter close to the unit related to the ratio between the critical volume for a relaxation process to take place and the volume of the segments involved in the process [46-47]. Assuming $B=1$, the value of the relative free volume $\phi_{g}$ at $T_{g}$ was $0.041 \pm 0.001$, whereas the value of the thermal expansion coefficient of the free volume $\alpha_{f}$ at $\mathrm{T}_{\mathrm{g}}$ amount to $(0.66 \pm 0.02) \times 10^{-3} \mathrm{~K}^{-1}$. It is worth noting that the value of $\phi_{g}$ is slightly higher than the value reported for this quantity for most flexible polymers, presumably due to the fact that the relaxation curves only extend over a rather limited span of frequency and temperature windows. On the other hand, the thermal expansion coefficient of the free volume $\alpha_{f}$ at $T_{g}$ is similar to the ones reported for the most flexible polymers [48].

\subsection{Dielectric measurements}

Figure 7 shows the variation of the dielectric permittivity and loss factor with temperature, at several frequencies for the 60VP-40BA membrane. In figure 7(a), it is observed that the dielectric permittivity $\varepsilon^{\prime}$ displays the same pattern for all isochrones, that is, a low temperature step associated with the glass rubber transition, or $\alpha$ relaxation process, followed by an important increase of the permittivity. This increase is related to the electrode polarization (EP), coming from the accumulation of charges at the electrode-polymer interface. On the other hand, figure 7(b) shows the isochrones 
corresponding to the dielectric loss $\varepsilon^{\prime \prime}$. The obtained spectrum is very similar to the one obtained from the mechanical measurements. In order to compare both spectra, in figure 7(c) are plotted the mechanical $\left(E^{\prime}\right)$ and the dielectric loss modulus $\left.\left(M^{\prime \prime}=\mathcal{E}^{\prime \prime}\right)\left(\mathcal{E}^{\prime}+\mathcal{E}^{\prime \prime}\right)\right)$ as a function of temperature at $1 \mathrm{~Hz}$. Both spectra clearly present two relaxational zones. In the low-temperature zone, we can observe the presence of two secondary relaxations, labelled as $\gamma$ and $\beta$ processes, presumably associated with side chain motions. In the high-temperature zone, both spectra present an ostensible $\alpha$ relaxation.

Moreover, in the dielectric spectrum a process associated with the conductivity phenomenon (EP) is observed. As a result of the strong conductivity contribution to $\varepsilon^{\prime \prime}$, it is observed a rather sharp increase of the loss factor as temperature increases (see figure 7(b)).
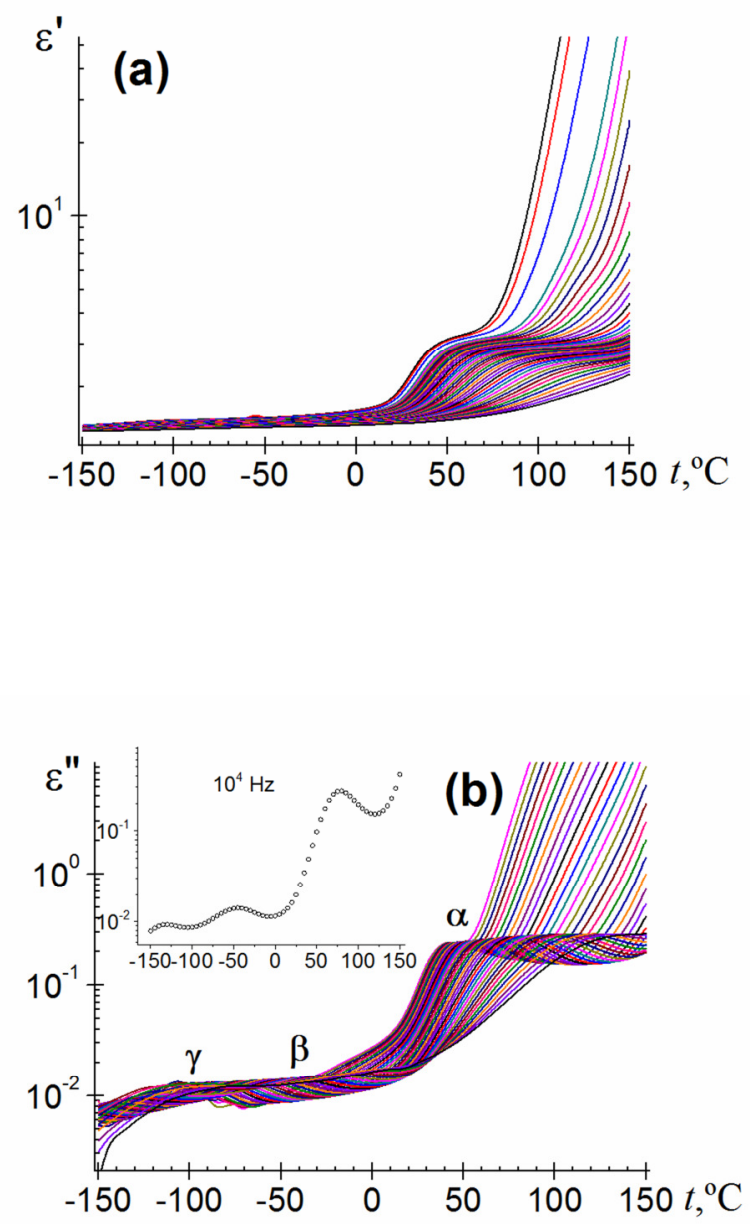


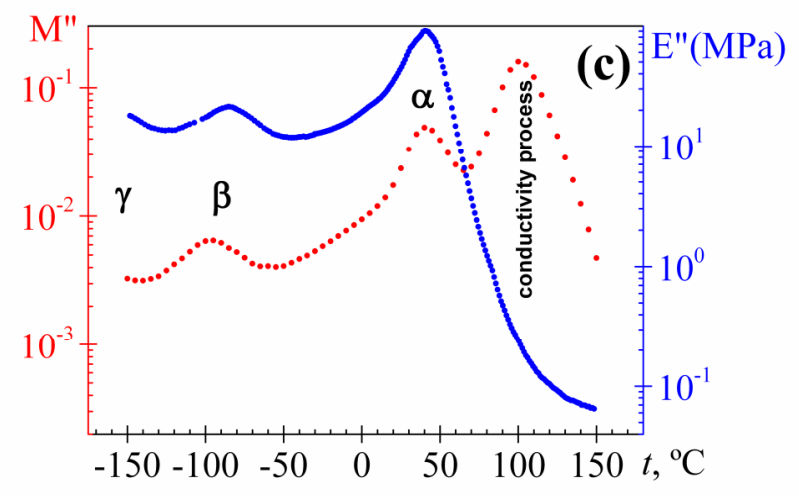

Figure 7. Temperature dependence of (a) permittivity and (b) loss permittivity at several frequencies and (c) loss dielectric modulus and loss mechanical modulus at $1 \mathrm{~Hz}$, for 60VP-40BA membrane.

For the convenience of further analysis and calculations, the dielectric permittivity was also plotted in the frequency domain. Isotherms for $\varepsilon^{\prime}$ in the frequency domain, corresponding to 60VP40BA membrane at several temperatures, are shown in figure 8(a). As usual, $\varepsilon^{\prime}$ increases as frequency decreases reaching a plateau corresponding to the relaxed dipoles ( $\alpha$ relaxation). After this plateau, it is observed a sharp increase of the permittivity with decreasing frequency, related to the presence of EP process. As a consequence of the strong EP process occurring at low frequencies, $\tan \delta$ exhibits a peak below the glass-rubber liquid relaxation. The pertinent peaks in the frequency domain are plotted at several temperatures in figure 9. 

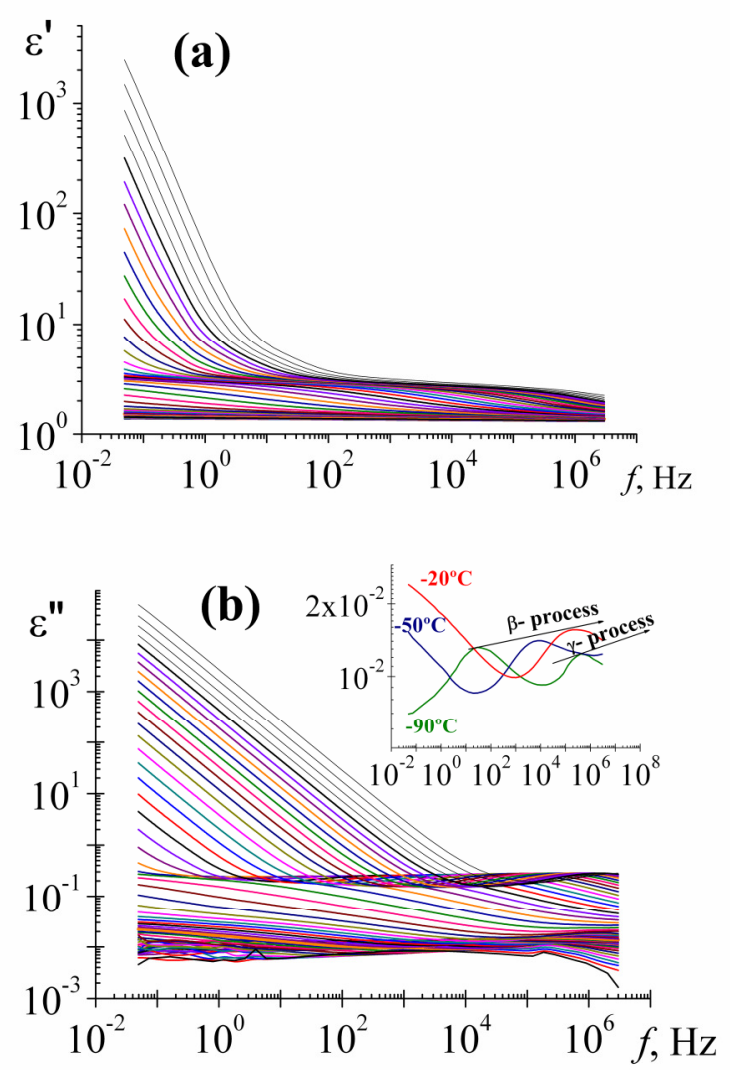

Figure 8. (a) Dielectric permittivity and (b) loss as a function of the frequency at temperatures between $-150^{\circ} \mathrm{C}$ to $150^{\circ} \mathrm{C}$ at step of $5^{\circ} \mathrm{C}$, for $60 \mathrm{VP}-40 \mathrm{BA}$ membrane.

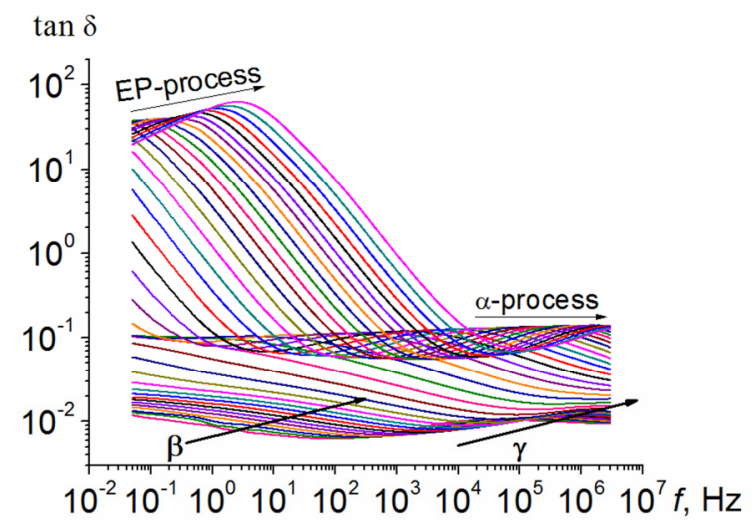

Figure 9. Loss $\tan \delta$ in the frequency domain for 60VP-40BA membrane at several temperatures ($110^{\circ} \mathrm{C}$ to $150^{\circ} \mathrm{C}$, step $5^{\circ} \mathrm{C}$ ).

Figure 8(b) shows the isotherms for $\mathcal{E}^{\prime \prime}$ in the frequency domain. As we can see, in order of decreasing frequencies, there are two secondary processes, labelled as $\gamma$ and $\beta$, and an $\alpha$ relaxation 
associated with the glass transition, dominated at low frequencies (specially at high temperatures) by strong conductive processes. To get insight of the complex conductive behaviour of 60VP-40BA membrane, it is advisable to use the electric modulus formalism [49] $\left(M^{*}=1 / \varepsilon^{*}\right)$ for the data representation. Better definitions of the loss peaks are obtained by plotting the dielectric results in terms of the dielectric loss modulus, $M^{\prime \prime}$. As we can see in figure 10, the isotherms of $M^{\prime \prime}$ exhibit two ostensible peaks corresponding in decreasing order of frequency to the $\alpha$-relaxation and to the conductive process.

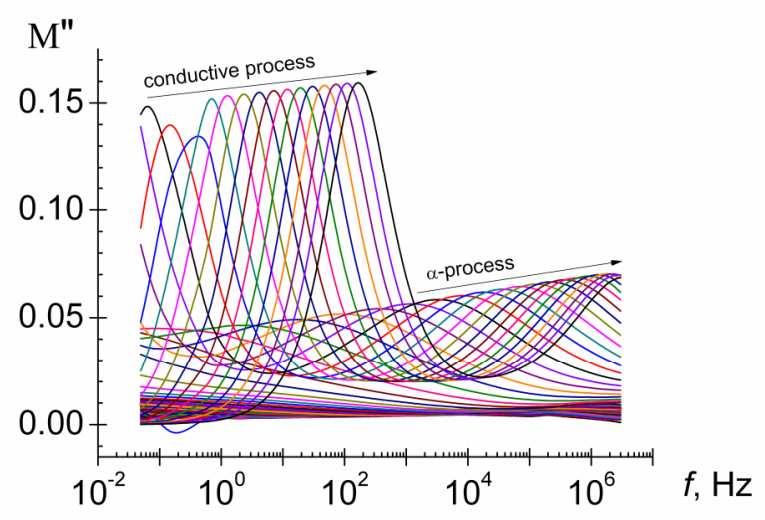

Figure 10. $M$ "in the frequency domain for 60VP-40BA membrane at several temperatures $\left(-110^{\circ} \mathrm{C}\right.$ to $150^{\circ} \mathrm{C}$, step $\left.5^{\circ} \mathrm{C}\right)$.

In order to a better visualization of each process, we have represented in figure 11 the frequency dependence of $\varepsilon^{\prime}, \varepsilon^{\prime \prime}$ and $\tan \delta$ at one temperature $\left(110^{\circ} \mathrm{C}\right)$ for the 60VP-40BA membrane.

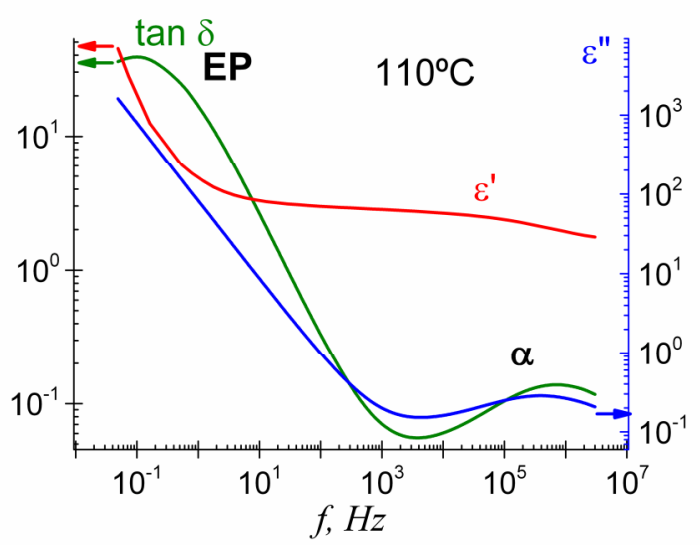

Figure 11. Frequency dependence of $\varepsilon^{\prime}, \varepsilon^{\prime \prime}$ and $\tan \delta$ for $60 \mathrm{VP}-40 \mathrm{BA}$ membrane, at $110^{\circ} \mathrm{C}$. 
The analysis of the dielectric spectrum was made by using the empirical equation of HavriliakNegami [50-52] which relates the complex permittivity $\left(\varepsilon^{*}\right)$ to the frequency by

$$
\varepsilon_{\text {dip }}^{*}(\omega)=\varepsilon_{\infty}+\frac{\varepsilon_{0}-\varepsilon_{\infty}}{\left[1+(j \omega \tau)^{a}\right]^{b}}
$$

where $\omega=2 \pi f$ is the angular frequency, the subscripts $\varepsilon_{0}$ and $\varepsilon_{\infty}$ are, respectively, the relaxed $(\omega=0)$ and unrelaxed $(\omega=\infty)$ dielectric permittivities, and $\tau$ is the relaxation time of the process. The shape parameters $a$ and $b$ fulfil the condition $0<a b \leq 1$, and for a Debye process $a=b=1$. The parameter $a$ is related to the departure of the complex $\varepsilon^{\prime \prime} v s \varepsilon^{\prime}$ plot from a semi-circumference at low frequencies (the lower is $a$, the higher the departure is). The parameter $b$ is related to the skewness of the plot along a straight line, at high frequencies. Equation (4) also describes the relaxation spectra of secondary absorptions with $b=1$.

At the high temperature region, where the conductive process is dominant, we have included a new term in order to characterize the spectrum: $\varepsilon^{*}(\omega)=\varepsilon_{\text {dip }}^{*}+\varepsilon_{\text {cond }}^{*}$ with $\varepsilon_{\text {cond }}^{*}(\omega)=j\left(\sigma / e_{0} \omega\right)^{s}$ where $e_{0}$ is the free space dielectric permittivity $\left(e_{0}=8.854 \mathrm{pF} \cdot \mathrm{m}^{-1}\right), \sigma$ is the conductivity arising from charges transport at the liquid-electrode interface and $s$ is a constant $(0 \leq s \leq 1)$.

The splitting of eq (4) in real and imaginary parts gives:

$$
\begin{aligned}
& \varepsilon^{\prime}(\omega)=\varepsilon_{\infty}+r^{-b / 2} \cdot\left(\varepsilon_{0}-\varepsilon_{\infty}\right) \cdot \cos b \theta \\
& \varepsilon^{\prime \prime}(\omega)=r^{-b / 2} \cdot\left(\varepsilon_{0}-\varepsilon_{\infty}\right) \cdot \sin b \theta
\end{aligned}
$$

where

$$
\begin{aligned}
& r=\left[1+\left(\omega \cdot \tau_{0}\right)^{a} \cdot \cos (a \cdot \pi / 2)\right]^{2}+\left[\left(\omega \cdot \tau_{0}\right)^{a} \cdot \sin (a \cdot \pi / 2)\right]^{2} \\
& \theta=\operatorname{arctg}\left[\frac{\left(\omega \cdot \tau_{0}\right)^{a} \cdot \sin (a \cdot \pi / 2)}{1+\left(\omega \cdot \tau_{0}\right)^{a} \cdot \cos (a \cdot \pi / 2)}\right]
\end{aligned}
$$

In the low temperature zone, for the analysis of the dielectric loss spectra an additive rule for the permittivity was assumed [53]. The HN parameters of the two secondary relaxations were determined at several temperatures from a multiple non-linear regression analysis of the experimental data, allowing the three characterizing peak parameters $\left(\Delta \varepsilon_{i}, \tau_{i}, a_{i}\right)$ to vary. For the high temperature zone the analysis was carried out by fitting the loss permittivity to the experimental results by means of 


$$
\varepsilon^{\prime \prime}(\omega)=r^{-b / 2} \cdot\left(\varepsilon_{0}-\varepsilon_{\infty}\right) \cdot \sin b \theta+\left(\frac{\sigma}{e_{0} \omega}\right)^{s}
$$

The HN and conductive fit parameters were determined like those obtained for the secondary relaxations.

The shape parameters associated with the relaxation processes of the 60VP-40BA membrane are shown in figure 12. For the $\alpha$ relaxation, the value of $a$ parameter slightly increases with increasing temperature. Moreover, the value of $b$ parameter, at all temperatures investigated, was 1 , so that the eq. (4) reduces to the Cole-Cole equation [54] that describes a relaxation with a symmetric distribution of relaxation times. For amorphous polymers, a non-symmetric distribution of times is expected for the $\alpha$ relaxation, associated with macromolecular segmental motion, at temperatures immediately above the glass transition. But for semi-crystalline polymers and more generally for heterogeneous systems, published data by Boyd [55], Laredo [56], Cebe [57], Noda [58], Ryabov [59], Janik [60], Feldman [61], Ortiz-Serna [29-30] etc., show that symmetrical distributions are observed for the $\alpha$ relaxation processes. However, the temperature dependence of $a$ for the $\beta$ process differs from that observed for the glass rubber relaxation since it decreases with temperature. Finally, the $a$ parameter for the $\gamma$-process remains nearly constant in the range of the analysed temperatures.

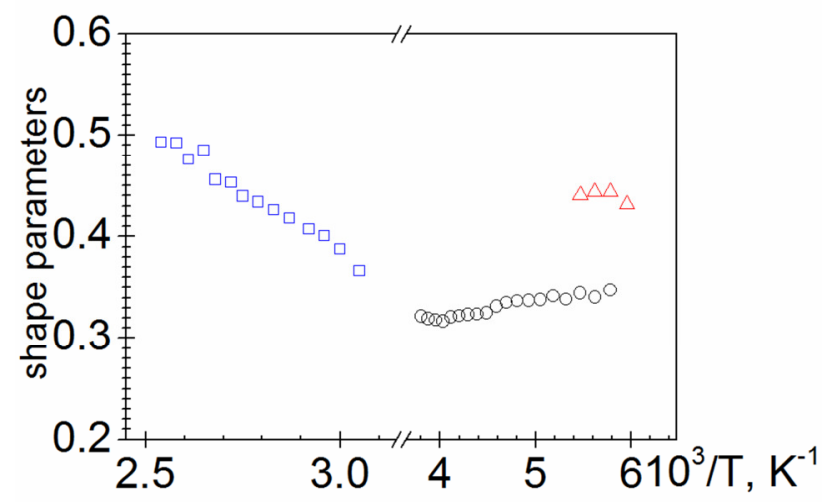

Figure 12. Temperature dependence of the shape parameters $a$ for $\alpha$ (squares), $\beta$ (circles) and $\gamma$ (triangles) relaxations. The $b$ parameter was for all temperature and all processes equal to 1 .

The temperature dependence of the relaxation strength is shown in figure 13. For all processes this dependence follows the classical trends, that is, the dielectric strengths for the $\beta$ and $\gamma$ absorptions increase and nearly remain constant with increasing temperature. Whereas, the strength of the $\alpha$ relaxation decreases with increasing temperature, due to the fact that thermal energy disturbs the 
alignment of the molecule dipoles, intervening in the cooperative motions that give rise to the relaxation.

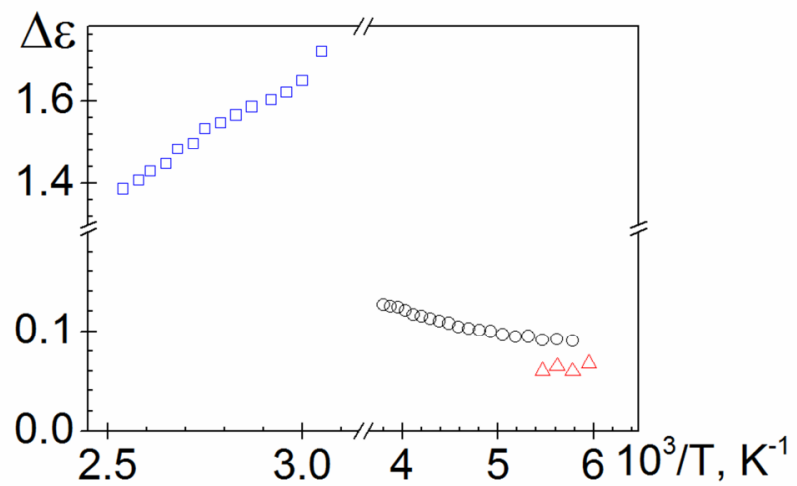

Figure 13. Temperature dependence of the strengths of the $\alpha$ (squares), $\beta$ (circles) and $\gamma$ (triangles) relaxations.

The temperature dependence of the relaxation times associated with the peak maxima of the primary and secondary absorptions is shown in figure 6 . It can be seen that the secondary relaxations exhibit Arrhenius behaviour. The activation energies associated with the $\beta$ and $\gamma$ processes are $49.5 \pm 2.1$ and $22.1 \pm 1.1 \mathrm{~kJ} \cdot \mathrm{mol}^{-1}$, respectively. The value of activation energy obtained for the $\beta$ process is very similar to the one found from the mechanical analysis.

As mentioned before, the temperature dependence of the primary or $\alpha$-relaxation is described by VFTH equation [24-26, 39-43]. The deviation of the $\alpha$ relaxation from the Arrhenius behaviour may be quantified by the fragility parameter $D_{0}$ [44-45] in a modified form of the VFTH equation given by

$$
\tau=\tau_{0} \cdot \exp \left(\frac{D_{0} \cdot T_{v}}{T-T_{v}}\right)
$$

where $\tau_{0}$ is a prefactor of the order of picoseconds and $T_{v}$ is the Vogel Temperature. The experimental data was fitted to eq. (8) and the obtained values for $\tau_{0}, T_{v}$ and $D_{0}$ parameters were of $2.2 \times 10^{-}$ ${ }^{11} \pm 4.5 \times 10^{-14} \mathrm{~s}, 247.4 \pm 4.9 \mathrm{~K}\left(-25.6 \pm 0.5^{\circ} \mathrm{C}\right)$ and $6.3 \pm 0.5$, respectively. As usual, the results for $T_{v}$ are nearly $50^{\circ} \mathrm{C}$ below those of $T_{g}$. Moreover, the fragility parameter obtained for this membrane is lower than 10, the frontier that separates fragile $\left(D_{0}<10\right)$ from strong $\left(D_{0}>10\right)$ glasses [43, 62-63]. 
As previously stated, by comparing eq (8) with the Doolittle expression [44-45], and taking into account that $M=D_{0} \cdot T_{v}$ it was obtained that the values of $\phi_{g} / B$ and $10^{4} \times \alpha_{f}$ are $4.0 \times 10^{-2} \pm 2.2 \times 10^{-3}$ and $6.4 \pm 0.6 \mathrm{~K}^{-1}$, respectively. As in the obtained values in the mechanical measurements, $\phi_{g} / B$ is slightly higher than the average value of $2.5 \times 10^{-2} \pm 5.0 \times 10^{-3}$ found for this parameter in most flexible polymers, whereas the results for $\alpha_{f}$ are in agreement with those reported for other flexible polymers [48], which lie in the vicinity of $5 \times 10^{-4} \mathrm{~K}^{-1}$. Therefore, these obtained values are in accordance with the ones obtained from mechanical measurements.

The normalized $\alpha$ relaxation in the time domain for 60VP-40BA membrane was calculated from the retardation loss spectra [64-65], evaluated from the HN fit parameters by means of the following expression

$$
\phi(t)=\frac{\int_{-\infty}^{\infty} L_{\alpha}(\ln \tau) e^{-t / \tau} d \ln \tau}{\int_{-\infty}^{\infty} L_{\alpha}(\ln \tau) d \ln \tau}
$$

As usual, the function $\phi(t)$ is described by the KWW equation [66]

$$
\phi(t)=\exp \left[-\left(t / \tau^{*}\right)^{\beta_{K W W}}\right]
$$

where $\tau^{*}$ is a characteristic relaxation time and the stretch exponent $\left(\beta_{K W W}\right)$ lies in the range $0-1$ and quantifies the extent of deviation from pure exponentially, i.e. the degree of the relaxation time dispersion, whereas the case $\beta_{K W W}=1$ refers to simple exponential behaviour. The KWW decay functions at different temperatures are shown in figure 14. In the inset, the respective temperature dependence of the characteristic relaxation time and the stretch exponent is shown. As usual, an increase of temperature produces a decrease in the characteristic relaxation time and an increase in the value of the stretch exponent. The evolution of the $\tau^{*}$ with the temperature obeys the VFTH equation, and the tendency of the stretch exponent can be related to the decreasing of intermolecular constraints (or coupling) between the relaxing units with increasing temperature.

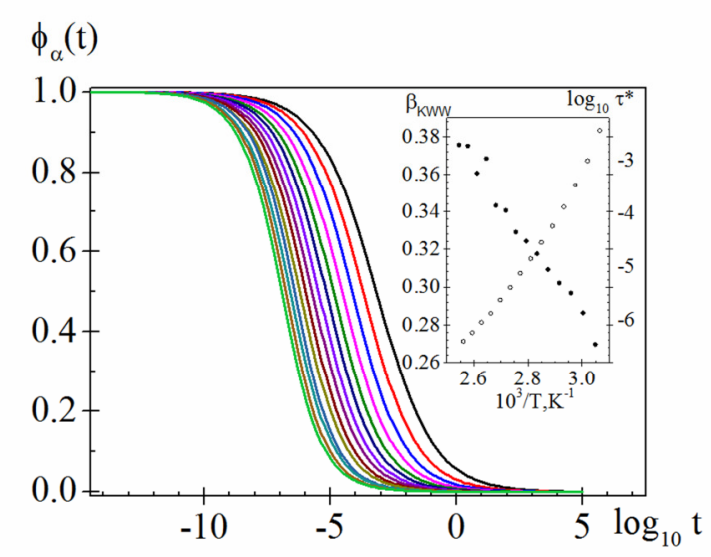


Figure 14. Normalized relaxation curves in the time domain for the $\alpha$ relaxation for 60VP-40BA membrane. The decay curves are fitted by the KWW equation using the stretch exponent $\beta_{\mathrm{KWw}}$ and the characteristic relaxation times $\tau^{*}$ shown in the inset of the figure.

The value of the ionic conductivity obtained from the experimental data fit to eq. (7) is plotted as a function of the reciprocal of temperature in figure 15(a). The estimated activation energy was of $116.7 \pm 1.7 \mathrm{~kJ} \cdot \mathrm{mol}^{-1}$. For the tested temperatures, the value of the $s$ parameter, in eq. (7), is in the range of 0.98 to 1 .
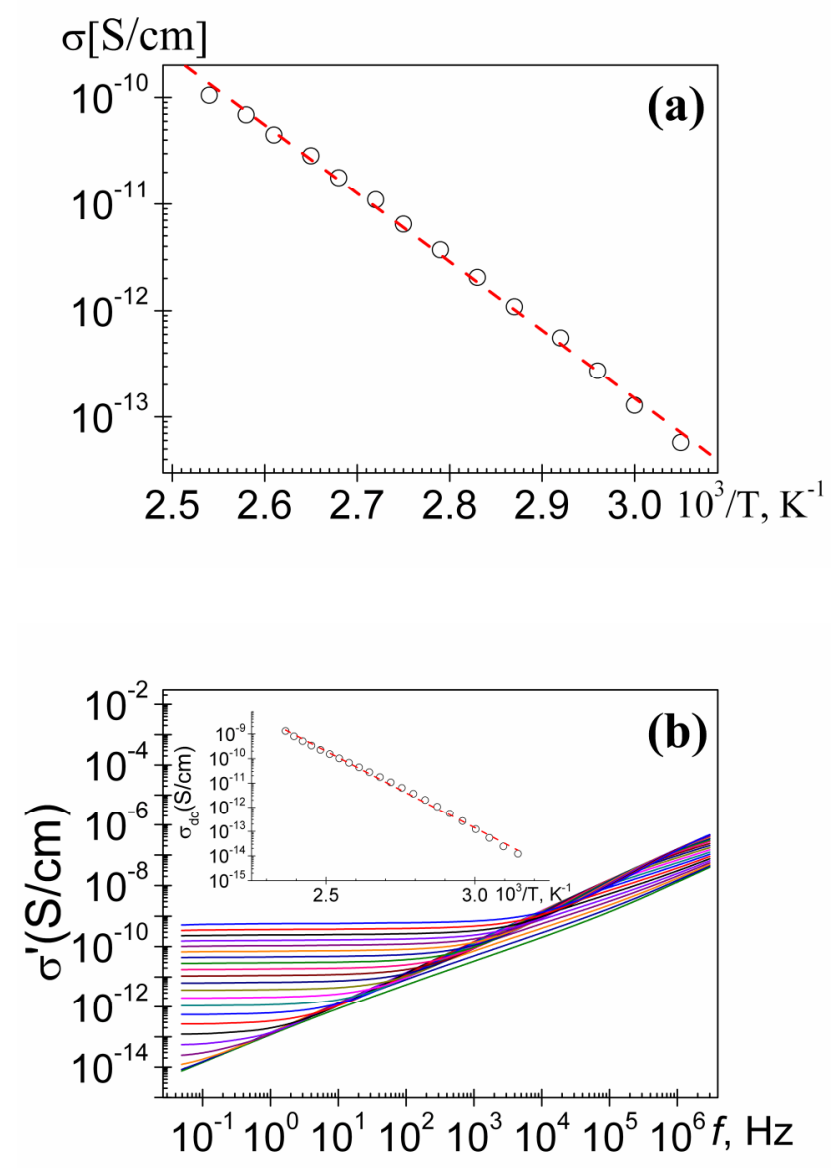

Figure 15. (a) Temperature dependence of the ionic conductivity evaluated by using eq. (7) and (b) $a c$ conductivity against frequency at temperatures in the range of $35^{\circ} \mathrm{C}$ to $130^{\circ} \mathrm{C}$ (step $5^{\circ} \mathrm{C}$ ) for $60 \mathrm{VP}$ 40BA membrane. Inset: Arrhenius plot of $d c$ conductivity. 
The ac conductivity has been calculated from the dielectric permittivity according to the relation: $\sigma^{*}(\omega)=j \cdot \omega \cdot e_{0} \cdot \varepsilon^{*}(\omega)$. In general at a constant temperature $a c$ conductivity can be expressed as [67-68]

$$
\sigma^{\prime}(\omega)=\sigma_{d c}+A \omega^{s}
$$

where $\sigma_{d c}$ is the frequency-independent conductivity $(\omega \rightarrow 0), A$ is a temperature dependent factor and $s$ is the frequency exponent $(0 \leq s \leq 1)$ also depending on the temperature. The eq. (11) is often called "the $a c$ universality law" since it has been found to satisfactorily describe the $a c$ response of numerous different types of materials, which can be classified as disordered solids [68-70].

Figure 15(b) depicts the dependence of the $a c$ conductivity from the frequency of the applied field at several temperatures in the range from $35^{\circ} \mathrm{C}$ to $130^{\circ} \mathrm{C}$ (step $5^{\circ} \mathrm{C}$ ). In the low frequencies and high temperatures zone, a frequency independent conductivity is recorded, which is attributed to resistive conduction through the bulk of polymer. On the other hand, when frequency is raised, the main displacement of the charge carriers is reduced. At this point the real part of conductivity, after reaching a certain frequency, appears to be proportional to frequency following the law $\sigma_{a c}^{\prime}(\omega) \sim \omega^{s}$ with $0 \leq s \leq 1$, characterizing hopping conduction. However, the influence of temperature is more pronounced in the low frequency range, while at high frequencies, the ac conductivity values approaching.

In the inset of figure 15(b) are plotted the values of $d c$ conductivity obtained at several temperatures from extrapolations to low frequencies as a function of the temperature reciprocal. As we can see, the dc conductivity is thermally activated and can be described by $\sigma_{d c}=\sigma_{0} \cdot \exp \left(-E_{d} / R T\right)$. The corresponding activation energy is $112.3 \pm 0.9 \mathrm{~kJ} / \mathrm{mol}$. This value is in accordance with the activation energy previously reported by the fitting of the experimental date to eq. (7).

\section{Conclusions}

The poly(vinylpyrrolidone-co-butyl acrylate) (60VP-40BA) membrane was chemically design to have a gel behaviour in water with a water swelling of $60 \%$. This fact permits a possible application of this material in biological media without a loss of an appropriate mechanical behaviour. In this regards, the membranes are highly tractable both in the dry and in the swollen state.

The 60VP-40BA membrane was mainly characterized by means of DSC, DRS and DMA techniques. All the employed techniques seem to keep into a good agreement between them, since the 
obtained $T_{g}$ values for the dry 60VP-40BA membrane were $38^{\circ} \mathrm{C}$ by DRS (at $1 \mathrm{~Hz}$ ), $37^{\circ} \mathrm{C}$ by DMA (at $1 \mathrm{~Hz}$ ) and $36^{\circ} \mathrm{C}$ by DSC. Not only $T_{g}$ values are in accordance, but also the percentage of water present in the sample due to the ambient humidity (2\%), which was estimated by means of DSC and by difference of weight (before and after drying until constant weight).

The VP and BA proportion was chosen to obtain a membrane with good mechanical and thermal properties. According to the TGA results, the material had reasonably good thermal stability. The DSC $T_{g}$ of the $60 \mathrm{VP}-40 \mathrm{BA}$ membrane $\left(36^{\circ} \mathrm{C}\right)$ lies between the poly-butyl acrylate $\left(-54^{\circ} \mathrm{C}\right)$ and the poly-vinylpyrrolidone $\left(100^{\circ} \mathrm{C}\right) \mathrm{Tgs}[13,71-72]$.

Results of DRS and DMA techniques showed two relaxation zones. At low temperatures and high frequencies two secondary relaxations, labelled in the decreasing order of temperature as $\beta$ and $\gamma$, are observed. The location and the activation energy value for the $\beta$ process were very similar in both, dielectric and mechanical measurements. The $\gamma$ relaxation only was characterized from dielectric measurements. According to the energetic barrier value obtained for $\gamma$ and $\beta$ relaxations, we concluded that these processes are related to the local motions that involve the side chain of the butyl-acrylate units [71,73-74] and with the rotation of the pyrrolidone group [75], respectively. On the other hand, at high temperatures and low frequencies, the $\alpha$ relaxation, related to the glass transition is observed in both spectra. The obtained characterizing parameters of this process were similar for the dielectric and mechanical measurements.

By DRS spectroscopy, dipolar data are contaminated by conductivity contribution at temperatures above the glass transition. This phenomenon is related to the electrode polarization (EP), coming from the accumulation of charges at the electrode-polymer interface. The activation energy of this process was evaluated by means of two procedures and in both cases the obtained value was similar.

\section{Acknowledgements}

B.R.F, M.C, P.O. and M.J.S., gratefully acknowledge to CICYT for grant MAT2012-33483. F.G. and J.M.G. acknowledge to the Spanish Ministerio de Economía y Competitividad-FEDER (MAT2011-22544) and the Junta de Castilla y León (BU001A10-2). 


\section{Figure Captions}

Figure 1. Chemical structures of the comonomers and the dense copolymer membrane.

Figure 2. FTIR spectra of the dried membrane.

Figure 3. TGA curves of the membranes in inert (nitrogen) and oxidizing (synthetic air) atmosphere.

Figure 4. DSC curve taken at $10 \mathrm{~K} \cdot \mathrm{min}^{-1}$ of $60 \mathrm{VP}-40 \mathrm{BA}$ membrane.

Figure 5. Temperature dependence of storage and loss modulus for 60VP-40BA membrane at $0.3,1$, 3, 10 and $30 \mathrm{~Hz}$.

Figure 6. Arrhenius plot for the $\alpha$ (square), $\beta$ (circles) and $\gamma$ (triangles) relaxations for 60VP-40BA membrane. Open symbols for dielectric results and full symbols for mechanical results.

Figure 7. Temperature dependence of (a) permittivity and (b) loss permittivity at several frequencies for 60VP-40BA membrane.

Figure 8. (a) Dielectric permittivity and (b) loss as a function of the frequency at temperatures between $-150^{\circ} \mathrm{C}$ to $150^{\circ} \mathrm{C}$ at step of $5^{\circ} \mathrm{C}$, for $60 \mathrm{VP}-40 \mathrm{BA}$ membrane.

Figure 9. Loss $\tan \delta$ in the frequency domain for 60VP-40BA membrane at several temperatures ($110^{\circ} \mathrm{C}$ to $150^{\circ} \mathrm{C}$, step $\left.5^{\circ} \mathrm{C}\right)$.

Figure 10. $M$ "in the frequency domain for 60VP-40BA membrane at several temperatures.

Figure 11. Frequency dependence of $\varepsilon^{\prime}, \mathcal{\varepsilon}^{\prime \prime}$ and $\tan \delta$ for 60VP-40BA membrane, at $110^{\circ} \mathrm{C}$.

Figure 12. Temperature dependence of the shape parameters $a$ for $\alpha$ (squares), $\beta$ (circles) and $\gamma$ (triangles) relaxations. The $b$ parameter was for all temperature and all processes equal to 1 .

Figure 13. Temperature dependence of the strengths of the $\alpha$ (squares), $\beta$ (circles) and $\gamma$ (triangles) relaxations.

Figure 14. Normalized relaxation curves in the time domain for the $\alpha$ relaxation of 60VP-40BA membrane The decay curves are fitted by the KWW equation using the stretch exponents $\beta_{\mathrm{KWw}}$ and the characteristic relaxation times $\tau^{*}$ shown in the inset of the figure. 
Figure 15. (a) Temperature dependence of the ionic conductivity evaluated by using eq. (7) and (b) $a c$ conductivity against frequency at temperatures in the range of $35^{\circ} \mathrm{C}$ to $130^{\circ} \mathrm{C}$ (step $5^{\circ} \mathrm{C}$ ) for $60 \mathrm{VP}$ 40BA membrane. Inset: Arrhenius plot of $d c$ conductivity.

\section{References}

[1] A. Manuel Stephan, 2006 European Polymer Journal 42 21-42

[2] Suk-kyun Ahn, Rajeswari M. Kasi, Seong-Cheol Kim, Nitin Sharmaa and Yuxiang Zhoub 2008 Soft Matter 4 1151-1157

[3] Ju, H.K.; Ki, S.J.; Lee, Y.M. J. Appl. Polym. Sci. 2002, 83, 1128-1139.

[4] Devine, D.M., Higginbotham, C. L. Polymer 2003, 44, 7851-7860.

[5] Peppas, N.A.; Bures, P.; Leobandung, W.; Ichikawa, H. Eur. J. Pharm. Biopharm. 2000, 50, $27-$ 46.

[6] Peppas, N.A. Hydrogels in medicine and pharmacy. Florida: CRC Press, 1987.

[7] Wichterle O 1971 Encyclopedia of Polymer Science and Technology. (N.M. Bikales, Ed., Interscience, New York Vol. 15, p. 273)

[8] A. Yamauchi, 2001 Gels Handbook, Vol.1 The Fundamentals (Academic Press 4-12)

[9] Nguyen KT, West JL 2002 Biomaterials 23 4307-4314

[10] Lopérgolo LC, Lugao AB, Catalani LH 2003 Polymer 44 6217-6222

[11] Grassi M, Colombo I, Lapasin R 2000 J. Control. Release 68 97-113

[12] Folttmann H, Quadir A 2008 Drug Del. Tech 8 22-27

[13] Haaf F, Sanner A, Straub F. 1985 Polym. J. 17 143-152

[14] Rönnau AC, Wulferink W, Unver E, Ruzicka T, Krutmann J, Grewe M Br 2000 J. Dermatol. 143 1055-1058

[15] Adachi A, Fukunaga A, Hayashi K, Kunisada M, Horikawa T. 2003 Contact Dermatitits 48 133-136

[16] Yanez F, Concheiro A, Alvarez-Lorenzo C 2008 Eur. J. Pharm. Biopharm. 69 1094-1110

[17] Huglin MB, Zakaria MB 1986 J. Appl. Polym. Sci. 31 457-475

[18] 'H El Kaoutit, P Estevez, S Ibeas, F C Garcia, F Serna, F B Benabdelouahab, J M Garcia; Dyes and Pigments 96: (2013) 414-423.

[19] S Vallejos, P Estevez, S Ibeas, F Garcia, F Serna, J.M. Garcia; Sensors; 12: (2012) 2969-2982

[20] S Vallejos, A Munoz, F C Garcia, F Serna, S Ibeas, J M Garcia Journal of Hazardous Materials 227-228 (2012):480-483

[21] S Vallejos, P Estevez, S Ibeas, A Muñoz, F C García, F Serna, J M Garcia; Sensors \& Actuators: B. Chemical 157: (2011) 686-690

[22] Hart EV, Waxman BH 1983 In Encyclopedia of Chemical Technology (Mark, H.; Othmer, D.F.; Overberger, C.G.; Seaborg, G.T. Eds.; Interscience: New York,; Vol. 23, p. 967) 
[23] Gallardo A, Lemus AR, San Roman J, Cifuentes A, Diez-Masa J.C. 1999 Macromolecules 32 610-617

[24] McCrum NG, Read BE, Williams W. 1991 In Anelastic and Dielectric Effects in Polymeric Solids (Dover Publications: New York)

[25] Kremer F, Schönhals A 2003 In Broadband Dielectric Spectroscopy (Springer: Berlin)

[26] Riande E, Díaz-Calleja R 2004 In Electrical Properties of Polymers (Dekker, M., Ed.; The United States of America)

[27] Riande E, Díaz-Calleja R, Prolongo MG, Masegosa RM, Salom C 2000 Polymer Viscosity (Dekker, M., Ed.: The United States of America)

[28] Craig DQM 1995 Dielectric Analysis of Pharmaceutical Systems (Taylor\&Francis Ltd: London)

[29] Ortiz-Serna P, Díaz-Calleja R, Sanchis MJ, Riande E, Nunes R, Martins A, Visconte L 2010 Macromolecules 43 5094-5102

[30] Ortiz-Serna P, Díaz-Calleja R, Sanchis MJ, Riande E, Nunes R, Martins A, Visconte L $2011 \mathrm{~J}$. Non-Cryst. Solids 357 598-604

[31] Bower DI 2002 An Introduction to Polymer Physics (Cambridge University Press)

[32] Carsi M, Sanchis MJ, Diaz-Calleja R, Riande E, Nugent MJD 2012 Macromolecules 45 $3571-3580$

[33] Sanchis MJ, Carsí M, Ortiz-Serna P, Domínguez-Espinosa G, Díaz-Calleja R, Riande E, Alegría L, Gargallo L, Radic D 2010 Macromolecules 43 5723-5733

[34] Vallejos S, El Kaoutit H, Estévez P, García FC, de la Peña JL, Serna F, García JM 2011 Polym. Chem. 2 1129-1138

[35] Weinmüller C, Langel C, Fornasiero F, Radke CJ, Prausnitz JM 2006 J. Biomed. Mater. Res. A 77 230-241

[36] Jablonski AE, Lang AJ, Vyazovkin S 2008 Thermochim Acta 474 78-80

[37] Fuoss R, Kirkwood JG 1941 J Am Chem Soc 63 385-394

[38] ref. 24, pp. 118

[39] Vogel H 1921 Z Phys. 22 645-646

[40] Fulcher GS 1925 J Am Ceram Soc. 8 339-340

[41] Tamman G,.Hesse W 1926 Z Anorg Allg Chem. 156 245-247

[42] Lunkenheimer P, Schneider U, Brand R, Loidl A 2000 Contemp. Phys. 41 15-36

[43] Angell C A 1995 Science 267 1924-1935

[44] Doolittle A 1951 J. Appl. Phys. 22(12) 1471-1975

[45] Doolittle AK 1952 Appl. Phys. 23(2) 236-423

[46] Bueche F 1959 J. Chem. Phys. 30 748-752

[47] Cohen MH, Turnbull D 1959 J. Chem. Phys. 31 1164-1169 
[48] Ferry JD 1961 Viscoelastic Properties of polymers (2nd ed.; John Wiley\&Sons: New York)

[49] Hodge IM, Ngai KL, Moynihan CT 2005 J. Non-Cryst. Solids 351(2) 104-115

[50] Havriliak S, Negami S 1967 Polymer 8(4) 161-210

[51] Havriliak S, Negami S 1966 J. Polym. Sci. Part B Polym. Symp. 14 99-117

[52] Havriliak S, Negami S 1997 Dielectric and Mechanical Relaxation in Materials (Hanser: Munich, p 57)

[53] Donth E 1996 J. Polym. Sci. Part B Polym. Phys. 34(17) 2881-2892

[54] Cole KS, Cole RH 1941 J. Chem. Phys. 9 341-351

[55] Boyd RH 1985 Polymer 26 323-347

[56] Laredo E, Grimau M 2003 Macromolecules 36, 9840-9850

[57] Huo P, Cebe P 1992 J. Polym. Sci. Part B Polym. Phys. 30 239-250

[58] Noda N 2005 Polymer 46 7201-7217

[59] Ryabov Y, Nuriel H 2003 J. Polym. Sci. Part B Polym. Phys. 41(3) 217-223

[60] Janik P, Paluch M 2001 Physical Review E. 64042502

[61] Feldman Y, Puzenko A, Ryabov Y 2002 Chem. Phys. 284 139-168

[62] Angell CA 1996 In Complex Behavior of Glassy Systems (Proceedings of the XIV Sitges Conference, Sitges, Barcelona, Spain)

[63] Rubi M, Pérez-Vicente C 1997 (Eds.Springer, Berlin)

[64] Tamman G, Hesse W 1926 Z. Anorg Allg 156 245-247

[65] Kohlrausch F 1854 Progg Ann Phys Chem 91 179-214

[66] Williams G 1979 Adv. Polym. Sci. 33 59-92

[67] Böttger H, Bryskin UV 1985 Hopping conduction in solid (Akademie Verlag: Berlin, p. 169213)

[68] Jonscher AK 1992 Universal relaxation law (Chelsea Dielectric Press: London, Chapter 5)

[69] Dyre J.C, Shrøder TB 2000 Rev. Mod. Phys. 72(3) 873-892

[70] Dyre JC 1988 J. Appl. Phys. 64(5) 2456-2468

[71] Fulcher GS 1925 J. Am. Ceram. Soc. 8 339-340

[72] Mark JE 2007 Physical Properties of Polymer Handbook (Ed. Springer: Chapter 13, p. 220)

[73] Cerrada M.L, de la Fuente JL, Fernández-García M, Madruga EL 2001 Polymer, 42 4647-4655

[74] Sanchis MJ, Díaz-Calleja R Pelissou O, Gargallo L, Radic D 2004 Polymer 45 1845-1855

[75] Zhang S, Painter PC, Runt J 2004 Macromolecules 37(7) 2636-2642 


\section{Supplementary data}

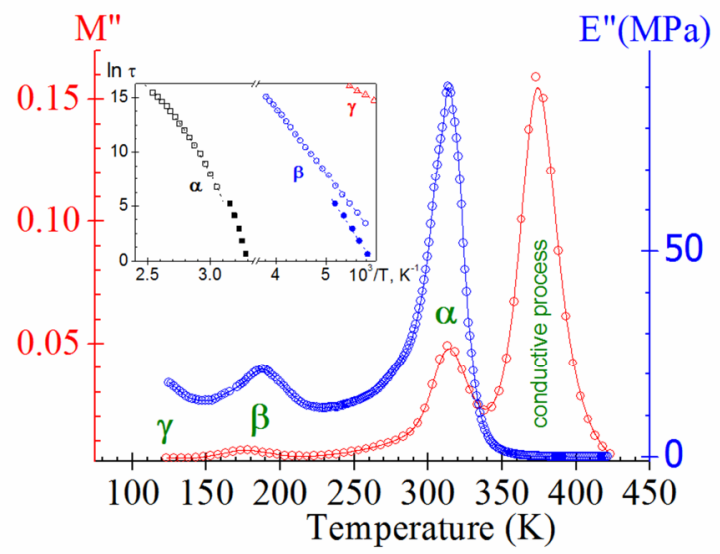

Relaxational Study of poly(vinylpyrrolidone-co-butyl acrylate) membrane by Dielectric and Dynamic mechanical Spectroscopy

B. Redondo-Foj ${ }^{1}$, M. Carsí ${ }^{1}$, P. Ortiz-Serna ${ }^{1}$, M.J. Sanchis ${ }^{*}$, F. García ${ }^{2}$, J.M. García ${ }^{2}$

${ }^{I}$ Instituto Tecnológico de la Energía, Departamento de Termodinámica Aplicada, ETSII, Universitat Politècnica de València, Camí de Vera s/n, 46022, Valencia, Spain.

${ }^{2}$ Universidad de Burgos, Plaza Misael Bañuelos s/n, 09001 Burgos, Spain.

*Corresponding author: M.J. Sanchis; Tel.: 0034963879327; email: jsanchis@ter.upv.es 
